www.jmscr.igmpublication.org

Impact Factor 5.84

Index Copernicus Value: 83.27

ISSN (e)-2347-176x ISSN (p) 2455-0450

crossref DOI:_https://dx.doi.org/10.18535/jmscr/v5i5.60

\title{
Comparative Study of Intravenous Phenylephrine with Mephenteramine for Maintenance of Arterial Blood Pressure in Caesarean Section
}

\author{
Authors \\ Dr Sunish B.S ${ }^{1}$, Dr Chitra V.R \\ ${ }^{1}$ Associate Professoe, Anaesthesiology, Medical College, Kottayam \\ ${ }^{2}$ Associate Professor, Govt .Medical College, Thiruvananthapuram
}

\begin{abstract}
Background: Anaesthesia for caesarean section has been a challenge for anesthesiologists for centuries. Advantages of regional anaesthesia especially, spinal anaesthesia has been documented as early as 1940s by Adrian et al. The advantages being simplicity of administration, reliability of action, faster onset than epidural and minimum effects on foetus. The major drawback was hypotension associated which is a result of sympathetic block. Intravenous vasopressors are the treatment of choice for the quick correction of hypotension. This study was undertaken to compare the effects of phenylephrine and mephenteramine for maintenance of blood pressure during caesarean section.
\end{abstract}

Aim

1. To compare the hemodynamic effects in the mother caused by phenylephrine and mephenteramine after spinal anaesthesia using $0.5 \%$ Bupivacaine.

2. To assess the requirement of repeated doses of each drug for maintenance of arterial pressure.

3. To assess the effects on neonate by APGAR score.

4. To look for side effects if any, caused by the drugs.

Keywords: Hypotension, Casarean section, Phenylephrine, Mephenteramine.

\section{Materials and Methods}

Approval from ethical committee was obtained. This was a double blind study done at SAT Hospital, Thiruvananthapuram. The study group included 40 patients, age between 20 - 35 years undergoing caesarean section.

\section{Inclusion Criteria}

- ASA1 and 2 full term parturients for elective and emergency caesarean section.

\section{Exclusion Criteria}

- Uncontrolled PIH

- Uncontrolled GDM

- Height less than $150 \mathrm{~cm}$
- Foetal distress

- Malformed maternal spine

- Heart disease in mother

All patients underwent pre anaesthetic check up. Basal heart rate and blood pressure, both systolic and diastolic were recorded. Parturients were divided by lot method into 2 groups of 20 each.

Group P: Phenylephrine: 100 micrograms

Group M; Mephenteramine: 6 milligram

\section{Premedication}

All patients were given Inj. Metoclopramide 10 $\mathrm{mg}$ and Inj. Ranitidine $50 \mathrm{mg}$ half an hour before surgery after putting $18 \mathrm{G} \mathrm{I} / \mathrm{V}$ cannula in the non 
dominant hand. Inj. Ringer Lactate $10 \mathrm{ml} / \mathrm{kg}$ was given for preloading. Anaesthesia machine, Bain"s circuit, Laryngoscopes, various ET tubes kept ready .All emergency drugs also kept ready.

\section{Monitors}

Patients were connected to ECG monitor, NIBP, $\mathrm{SpO} 2$ monitors. After preloading, pulse rate, systolic blood pressure, diastolic blood pressure were recorded.

\section{Procedure}

LSAB was given in right lateral decubitus position at L3.4 interspace using $25 \mathrm{G}$ spinal needle .Then $1.6 \mathrm{ml} 0.5 \%$ Bupivacaine (heavy) was given .Patient was made supine and a wedge was placed under right buttock. Oxygen at a rate of $4 \mathrm{ml} /$ minute was administered through simple face mask. Normal Saline at a rate of $10-15 \mathrm{ml} / \mathrm{min}$ was given after LSAB .After delivery of baby, Inj. Oxytocin 10 Units was given by slow I/V injection. Once umbilical cord is clamped ,Inj. Oxytocin 20 units was given in a separate unit of normal saline as slow infusion.

\section{Study Method}

Pulse rate Systolic BP, Diastolic BP are meticulously recorded after LSAB. Whenever hypotension (fall in systolic pressure $>20 \%$ from the baseline value) or a value less than $90 \mathrm{~mm} \mathrm{Hg}$, study drug was given as intravenous bolus.

Pulse rate, systolic BP and diastolic BP are then recorded at every 2 minutes after the drug was given for 30 minutes and thereafter every 5 minutes till the end of surgery. The duration of study was limited to 30 minutes following the initial bolus of the vasopressor. The number of boluses needed were recorded. Bradycardia, (pulse rate of 60/min or less) was treated with Inj. Atropine $0.6 \mathrm{mg} \mathrm{I} / \mathrm{V}$. The highest level of sensory block was assessed by pin prick method (1).After the subarachnoid block and delivery (2). Subarachnoid block and occurrence of first episode of hypotension and (3) Uterine incision and delivery were noted.
APGAR scores were assessed 1 and 5 minutes after delivery by attending paediatrician, who was blinded to the patients group. A double clamped segment of umbilical cord was kept for immediate blood gas analysis in case APGAR was less than 7.Blood loss was assessed by volume in the suction bottle and by the number of soaked sponges. Patient was monitored throughout the procedure and for a minimum period of 1 hour in the postoperative recovery room before transferring her from the operating room suite.

\section{Statistical Analysis}

Data were analysed using computer software, SPSS. Students t test was performed as parametric test to compare different variables. For all statistical evaluations, a two tailed probability value $\mathrm{p}$ value, 0.05 was considered significant.

\section{Observations}

Table 1 Patient Profile

\begin{tabular}{|l|c|c|c|}
\hline Variable & P & M & P value \\
& Mean & Mean & \\
\hline Age in years & 28.10 & 27.70 & 0.718 \\
& 3.64 & 3.31 & \\
\hline Height in cm & 155 & 155.50 & 0.447 \\
& 2.08 & 2.04 & \\
\hline Weight in kg & 56.30 & 56.30 & 1.000 \\
& 1.89 & 2.00 & \\
\hline
\end{tabular}

So, both the groups were comparable with each other.

2.Level of Sensory Block

\begin{tabular}{|l|c|c|c|}
\hline & T4 & T5 & T6 \\
\hline $\mathrm{P}$ & 5 & 14 & 1 \\
\hline $\mathrm{M}$ & 1 & 15 & 4 \\
\hline
\end{tabular}

3. (a).LSAB - Hypotension interval

\begin{tabular}{|l|c|c|}
\hline & Mean & SD \\
\hline $\mathrm{P}$ & 160.85 & 42.21 \\
\hline $\mathrm{M}$ & 185.10 & 42.42 \\
\hline \multicolumn{2}{|c|}{$\mathrm{P}$ values between $\mathrm{M}$ and $\mathrm{E}$ is 0.078.}
\end{tabular}

3.(b) LSAB - Delivery of baby interval

\begin{tabular}{|l|c|c|}
\hline & Mean & SD \\
\hline $\mathrm{P}$ & 261.55 & 52.80 \\
\hline $\mathrm{M}$ & 293.60 & 61.25 \\
\hline
\end{tabular}

$\mathrm{P}$ value between the groups was 0.084 
3.(c): Time interval between uterine incision and delivery of baby(UD Interval)

\begin{tabular}{|l|c|c|}
\hline & Mean & SD \\
\hline $\mathrm{P}$ & 57.75 & 10.48 \\
\hline $\mathrm{M}$ & 64.00 & 17.96 \\
\hline
\end{tabular}

$\mathrm{P}$ value was 0.187 .

4 Systolic BP: Comparison between Group P and Group M

\begin{tabular}{|l|c|c|c|}
\hline & T value & df & P value \\
\hline Basal value & 0.020 & 38 & 0.984 \\
\hline HP-VP & 0.445 & 38 & 0.659 \\
\hline $2 \mathrm{mts}$ after VP & 5.619 & 38 & 0.000 \\
\hline $4 \mathrm{Mts}$ & 2.036 & 38 & 0.049 \\
\hline $6 \mathrm{mts}$ & 2.012 & 38 & 0.047 \\
\hline $8 \mathrm{mts}$ & 1.995 & 38 & 0.053 \\
\hline $10 \mathrm{mts}$ & 1.444 & 38 & 0.157 \\
\hline $12 \mathrm{mts}$ & 1.496 & 38 & 0.143 \\
\hline $14 \mathrm{mts}$ & 0.333 & 38 & 0.741 \\
\hline $16 \mathrm{mts}$ & 1.787 & 38 & 0.082 \\
\hline $18 \mathrm{mts}$ & 1.328 & 38 & 0.192 \\
\hline $20 \mathrm{mts}$ & 2.068 & 38 & 0.068 \\
\hline $25 \mathrm{mts}$ & 1.714 & 38 & 0.095 \\
\hline $30 \mathrm{mts}$ & 1.890 & 38 & 0.066 \\
\hline
\end{tabular}

In both groups, systolic BP falls at the onset of hypotension from the basal value and then rises after bolus. Group P showed a rapid restoration of BP in the $2^{\text {nd }}, 4^{\text {th }}$ and $6^{\text {th }}$ minute after bolus injection in a statistically significant manner. From $8^{\text {th }}$ to 30 th minute, there was a rise in SBP in both groups, but was not significant statistically.

5 Diastolic BP: Intergroup Comparison

\begin{tabular}{|l|c|c|c|}
\hline & $\mathrm{t}$ & $\mathrm{df}$ & $\mathrm{P}$ value \\
\hline Basal value & 1.299 & 38 & 0.202 \\
\hline HP-VP & 0.827 & 38 & 0,413 \\
\hline $2 \mathrm{mts}$ after VP & 5.057 & 38 & 0.000 \\
\hline $4 \mathrm{mts}$ & 4.357 & 38 & 0.000 \\
\hline $6 \mathrm{~min}$ & 3.531 & 38 & 0.001 \\
\hline $8 \mathrm{~min}$ & 1.988 & 38 & 0.054 \\
\hline $10 \mathrm{~min}$ & 1.822 & 38 & 0.076 \\
\hline $12 \mathrm{~min}$ & 0.947 & 38 & 0.0349 \\
\hline $14 \mathrm{~min}$ & 1.822 & 38 & 0.076 \\
\hline $16 \mathrm{~min}$ & 1.333 & 38 & 0.190 \\
\hline $18 \mathrm{~min}$ & 1.988 & 38 & 0.054 \\
\hline $20 \mathrm{~min}$ & 1.333 & 38 & 0.190 \\
\hline $25 \mathrm{~min}$ & 0.947 & 38 & 0.349 \\
\hline $30 \mathrm{~min}$ & 1.333 & 38 & 0.190 \\
\hline
\end{tabular}

In both groups, diastolic BP also falls at the onset of hypotension from the basal value and then rises after bolus .Group P showed a rapid restoration of
BP in the $2^{\text {nd }}, 4^{\text {th }}$ and $6^{\text {th }}$ minute after bolus injection in a statistically significant manner. From $8^{\text {th }}$ to 30 th minute, there was rise in the diastolic BP, but was not statistically significant between the groups.

6. Changes in Heart Rate: Intergroup Comparison

\begin{tabular}{|l|c|c|c|}
\hline \multicolumn{1}{|c|}{$\mathrm{t}$} & $\mathrm{df}$ & $\mathrm{P}$ value \\
\hline Basal value & 1.691 & 38 & 0.099 \\
\hline HP-VP & 2.7 & 38 & 0.008 \\
\hline $2 \mathrm{~min}$ after VP & 10.465 & 38 & 0.000 \\
\hline $4 \mathrm{~min}$ & 10.804 & 38 & 0.000 \\
\hline $6 \mathrm{~min}$ & 6.224 & 38 & 0.000 \\
\hline $8 \mathrm{~min}$ & 7.288 & 38 & 0.000 \\
\hline $10 \mathrm{~min}$ & 7.649 & 38 & 0.000 \\
\hline $12 \mathrm{~min}$ & 7.587 & 38 & 0.000 \\
\hline $14 \mathrm{~min}$ & 12.524 & 38 & 0.000 \\
\hline $16 \mathrm{~min}$ & 10.136 & 38 & 0.000 \\
\hline $18 \mathrm{~min}$ & 8.686 & 38 & 0.000 \\
\hline $20 \mathrm{~min}$ & 8.805 & 38 & 0.000 \\
\hline $25 \mathrm{~min}$ & 10.62 & 38 & 0.000 \\
\hline $30 \mathrm{~min}$ & 11.122 & 38 & 0.000 \\
\hline
\end{tabular}

Heart rate was raised in both groups during hypotension. In group $\mathrm{P}$, heart rate decreased in a significant manner right from the $2^{\text {nd }}$ minute after the vasopressor was given .In most of the cases, the heart rate at the end of the study was less than the basal heart rate. In group $M$, the heart rate remained almost always elevated than the basal heart rate.

7. Bolus drug needed

\begin{tabular}{|l|c|c|}
\hline Bolus No. & P & M \\
\hline 1 & 5 & 11 \\
\hline 2 & 9 & 8 \\
\hline 3 & 6 & 1 \\
\hline
\end{tabular}

In group P,25 \% required single, $45 \%$ two ,30 \% three boluses to maintain blood pressure. Where as in group M,55 \% required single, $40 \%$ two and $5 \%$ three doses.

\section{APGAR Score}

\begin{tabular}{|l|c|c|c|}
\hline APGAR & $\mathrm{P}($ mean $)$ & $\mathrm{M}($ mean $)$ & $\mathrm{P}$ value \\
\hline 1 minute & 8.85 & 8.80 & 0.687 \\
\hline 5 minutes & 9.85 & 9.80 & 0.684 \\
\hline
\end{tabular}

APGAR score did not reveal any untoward effect on foetal status since all the newborns of two groups had APGAR > 7. 


\section{Discussion}

Spinal subarachnoid block has been the mainstay for caesarean sections for decades. The major disadvantage was post spinal headache. Prophylactic use of crystalloids by preloading has been a technique to prevent hypotension. Judicious use of vasopressors has been used to treat hypotension. In our study, all the patients received $10 \mathrm{ml} / \mathrm{kg}$ Ringer Lactate as preloading. Vasopressor of individual parturient was selected randomly. Mephenteramine has a mixed alpha and beta action, whereas Phenylephrine is a pure alpha agonist.

Thomas and colleagues reported that bolus Phenylephrine 100 microgram is as effective as Mephenteramine $6 \mathrm{mg}$ on restoring maternal arterial pressure above $100 \mathrm{mmHg}$.

Moran et al found a comparable efficacy in comparing 80 microgram phenylephrine and 10 $\mathrm{mg}$ mephenteramine boluses. They also concluded when used in small increment bolus injections, phenylephrine has no adverse neonatal effects in normal healthy parturients.

Hall and colleagues compared a prophylactic infusion of phenylephrine $10 \mathrm{microgm} / \mathrm{mt}$ with mephenteramine 1 or $2 \mathrm{mg} / \mathrm{min}$ supplemented by 20 micro gm or $6 \mathrm{mg}$ boluses respectively, if systolic arterial pressure decreased by $20 \%$ from baseline .Hall et al have remarked that maternal bradycardia in the phenylephrine group corresponded with periods when a number of bolus doses of phenylephrine had been given for maternal hypotension.

In our study, there was an initial fall in both systolic and diastolic blood pressures after spinal anaesthesia.

Phenylephrine showed a rapid restoration of blood pressure. Arterial pressures at 2,4,6 minutes after phenylephrine was greater than that compared to mephenteramine. This may be because phenylephrine has peak effect within one minute whereas mephenteramine within two to five minutes. The number of boluses of drug needed was more in phenylephrine group, suggesting the rapid onset of its action. In the $\mathrm{P}$ group, $25 \%$ needed single. 45
$\%$ needed two, $30 \%$ needed three boluses .In the M group. $55 \%$ needed single, $40 \%$ two ,5 \% three bolus doses.

On giving phenylephrine, heart rate decreased in some patients. Phenylephrine has the tendency to lower heart rate at 30 minutes than at baseline. Mephenteramine in fact raised the heart rate at 30 minutes than baseline value. In our study, none of the 40 participants of the study had babies of APGAR less than 8 either at 1 minute or at 5 minutes.

Blood loss was within allowable range for each and every parturient in the study.

The crystalloid preloading at the rate of $10-15$ $\mathrm{ml} /$ minute have also not confounded the results the height, weight and other maternal factors were comparable.

\section{Conclusion}

Our study shows that vasopressors, Phenylephrine hydrochloride and Mephenteramine hydrochloride used to treat hypotension during spinal anaesthesia for caesarean section when given as intravenous boluses of 100 micro gram and $6 \mathrm{mg}$ are comparable in their efficacy in maintenance of arterial pressure within $20 \%$ limit of baseline.

Regarding maintenance of systolic and diastolic blood pressure, phenylephrine showed a rapid restoration of blood pressure than mephenteramine.

Phenyl ephrine has a heart rate lowering effect, whereas mephenteramine shows a heart rate rising tendency.

The requirement of repeated doses was lower in mephenteramine group compared to phenylephrine due to rapid onset of action of phenylephrine. None of the two vasopresors had any effect on APGAR score or any maternal side effects.

We conclude that Phenylephrine and Mephenteramine are equally efficient in maintaining arterial pressures during spinal anaesthesia in caesarean section. 


\section{References}

1. E.T Riley,spinal anaesthesia for caesarean delivery .Keep the pressure up and don't spare the vasoconstrictors (Editorial) /British Journal of Anaesthesia 2004,vol 92.no.4.459-461.

2. Francis M,James Frank.C.Geiss.Richard .A.Kemp.An evaluation of vasopressor therapy for maternal hypotension during spinal anaesthesia. Anaesthesiology/July 1970.VOL 33No.1 25:34

3. Ecksteil KL,Marx GF.Aortocaval compression and uterine displacement. Anaesthesiology ,1974,40:92-96.

4. David .J.Bimbach and Ingrid.M.BrowneAnaesthesia for obstetrics in Millers Anaesthsia $6^{\text {th }}$ edn 2005 2307-2344.

5. David.H.Ralston,Sol.M.Schnider,Alfred A Lorimier. Effects of equipotent ephedrine, metaraminol. mephenteramine on uterine blood flow in the pregnant eve Anaesthesiology Vol.40.No.4.SApr 1974 pp354-369

6. David.H.Sprague-Effects of position and uterine displacement on spinal anaesthesia for LSCS Anaesthesiology Vol 44 NO.2 Feb 1976:pp 164-166.

7. Corker B.C.Data S,Steiner GW,Weiss GB, Alper MH.Spinal Anaesthesia for caesarean section. The influence of hypotension on neonatal outcome. Anaesthesia 1982:7:658-662.

8. Crawford JS .Burton M,Davies P, Anaesthesia fo CS, Further refinements of a technique.

9. British Journal of anaesthesia 973:45:726732.

10. Hall P A.Bennett aWilkes MP,Lewis M.Spinal anaestheaia for CS.Comparison of infusion of phenylephrine and mephenteramine.

11. Thomas DG ,Robson SC, Red fern, N.Hughes D.Boys RJ.Randomised trial of bolus phenylephrine or ephedrine for maintenance of arterial pressure in caesarean section

12. Levinson G,Schnider M,Vasopressors in Obstetics Clin.Anaesth.1974:10 (1 ) :77109.

13. Li TH,Shimosato.S,Gamble CA,Elstein BE,Hemodynamics of Mephenteramine during spinal anaesthsia in man .Anaesthesiology 1963:24:817-827.

14. Wylie and Churchhills Davidson A practice of Anaesthesia sixth edn.Edward Arnold 1995717.

15. Morgan P.Review article .Spinal Anaesthesia in obstetrics,Canadian Journal of Anaesthesia 1995,42,1145.63.

16. Ramanathan S,Maish A,Rock I,Chalom J,Turndorf H,Maternal and foetal effects of prophylactic hydration with colloids or crystalloids before epidural anaesthesia. Anaesthesia Analgesia 198362 673-8. 